\title{
Budget freeze taints French science plans
}

Paris. With only a few days to go before France's science minister, François Fillon, presents his plans for French research to the National Assembly, the finance ministry has pulled the rug from under his feet by freezing part of the budget for civil research and development.

The freeze may amount to as much as FF400 million (US\$68 million) in cash payments and FF500 in programme authorizations, equivalent to 8 per cent of the total research and development budget (excluding salaries).

The total promised research budget in 1994, at FF51.6 billion, was itself only 1.2 per cent up on the revised budget for 1993, and 2 per cent down on the original. Last year's revision cut cash payments by FF288 million, and programme authorizations by FF795 million.

Research organizations say it is too soon to predict the impact of the freeze, as they

\section{Soap giants trade blows over tests}

London. Two of the world's largest soap powder manufacturers have become locked in a war of words and figures over allegations of fabric damage caused by lowtemperature detergents containing a new manganese-based catalyst.

Last month, the Anglo-Dutch company Unilever launched a range of products containing the catalyst, which removes stains faster and at lower temperatures than older detergents. The catalyst is covered by more than 30 patents, and was developed at a reputed cost of more than $£ 100$ million.

Marketed in the United Kingdom as Persil Power and as Omo Power in the rest of Europe, the new Washday blues: Procter \& Gamble's 'evidence' (left) of the hazards of rival Unilever's new detergent.

catalyst is a heterocyclic complex of manganese that promotes the selective oxidation of stains by hydrogen peroxide.

Unilever claims that the catalyst is good news for the environment, as not only do low temperature washes save energy, but the production of the detergent requires both less energy and less water than traditional manufacturing methods.

But the company's US-based rival Procter \& Gamble, which manufactures Ariel, a leading soap powder, quickly claimed that the catalyst caused damage to garments under certain washing conditions.

The Dutch company was equally quick to take the US company to court, claiming it had made "untruthful and misleading statements". It subsequently dropped the charges, admitting that Persil Power could cause damage under "extreme conditions".

But the truce did not last long. Last week, Procter \& Gamble backed up its initial charges with a series of research reports from six independent European institutes apparently endorsing its conclusions, and producing pictures of faded and shredded garments allegedly washed in Persil Power.

Procter \& Gamble quoted excerpts from the reports saying that the fabric damage caused by the new formulations to cotton fabrics is "beyond the tolerances used to date for household detergents" and that this is "accelerated by certain dyes which can lead to holes well within the expected lifetime of the garment".

Unilever acknowledges that it has re-

\section{IMAGE \\ UNAVAILABLE \\ FOR COPYRIGHT REASONS}

duced the amount of manganese catalyst in its products. But the company says a little "fine-tuning" is normal in a product launch.

At the same time, the Anglo-Dutch company has challenged the results being quoted by its rival from one of the six institutes, the British Textile and Technology Group. In tests commissioned by Procter \& Gamble, the institute reported that Persil Power "totally destroyed" some garments after 50 wash cycles. But in separate tests commissioned by Unilever, the same institute found "no physical damage visible" on a range of articles after 15 and 25 washes.

"If you pick the right combination of dye, stains, material and basic colour, you can get results which will show severe damage," says Andrew Seth, chief executive of Unilever's UK detergents business. "If I wanted to, I could do the same with competing products."

The company has pledged to reimburse any customers who can prove their clothes have been damaged by Persil Power. Britain's Consumer Association is to carry out its own independent tests of the powders, and plans to produce a report in July.

Maggie Verrall have not yet been told how it will be distributed among individual agencies. But the Centre National de la Recherche Scientifique (CNRS), for example, spends more than three-quarters of its budget on salaries, and the freeze will therefore shrink still further the amount available for launching new research programmes and initiatives.

Researchers are also annoyed that the freeze comes half-way through the year, and therefore requires acrobatic accounting to limit the damage. Fillon says that a freeze is not a cancellation, and that he wants to restore the frozen funding. But observers in Paris point out that freezes rarely "thaw", and usually amount to straightforward cuts.

The move comes at a particularly bad moment for Fillon, a week before he presents his plans for research to the National Assembly. Fillon has argued that the spending cuts are unrelated to his plans for research. But the question of funding now threatens to overshadow next week's debate.

Moreover, the finance ministry's action may also damage the credibility of the science minister, who recently assured the research community, following a six-month national 'consultation' on research (see Nature 368,$675 ; 1994$ ), that spending on science would be maintained. Some are predicting that Fillon may seek a reduction in the freeze before next week's debate, in an effort to show himself as a defender of the scientific community.

In the longer term, the freeze raises questions about the government's commitment to science. Some scientists see the spectre of 1986, when research bore the brunt of more than half the cuts in spending by the incoming neo-Gaullist government, led by Jacques Chirac. It annulled the research budget of the previous socialist government, and held spending by the research organizations virtually constant.

Indeed, the finance ministry may see research as an easy target for cuts. The current freeze stems from the government's need to make public spending cuts of FF7 billion. In particular, the government is thought to be planning a reduction in interest rates in order to revive the economy, and therefore needs both to reduce the deficit and to prop up the franc to reassure the financial markets.

The freeze is not necessarily a bad omen for the research budget for 1995 . The government is taking unpopular measures before next year's presidential elections. Edouard Balladur, the prime minister and a possible presidential candidate, may increase public spending overall in next year's budget to build public confidence in his administration. But some cynics point out that this would not preclude the government from suddenly 'revising' the budget after the election.

Declan Butler 